\title{
Swarm Intelligent Application in Networks Routing Problem
}

\author{
Firas Ali Hashim \\ Computer Science Dept. \\ College of Science \\ Al- Mustansiriyah University \\ Baghdad, Iraq
}

\begin{abstract}
This paper presents an Ant Colony Optimization (ACO) approach used to find the optimal solutions in the routing problem; it is one of the swarm intelligent applications. The Proposed method is used to determine the optimal path from source to destination for any size of networks. Optimal Path means the less cost path. The packets are sent from source node to destination node throw all node from one to another, which are traveling through the computer network. ACO algorithm can successfully find the optimal path and reduce the time.
\end{abstract}

\section{Keywords}

Ant Colony Optimization (ACO), Swam Intelligent, Networks Routing, Optimal Path

\section{INTRODUCTION}

There are many accepted routing algorithms used to find the shortest path also to increase the throughput of networks. The goal of every network routing algorithm is to direct traffic from source to destination in order to maximize network performance [3], [7]. The optimal solution for choosing the best shortest path is to select the one with the smallest total cost (i.e., distances, time-spent) [8].

Ant Colony Optimization (ACO) is one of swam intelligent application used for solving complex computational problems, such as finding the optimal routes in networks [1], [4]. These techniques can be used to reduce time consumptions to solve telecommunication optimization problems, [10].

\section{ANT COLONIES}

ACO is an algorithm based on the behavior of the ants in finding a shortest path from a source "ant" to the destination "food". It has been observed that the ants deposit a certain amount of pheromone in its path while moving from its nest to food. Again, while come back to next ants follow the same path marked by the pheromone and again deposit the pheromone on path [2]. In this way the ants following the shortest Path (best path) are expected to return earlier and hence increase the amount of pheromone deposit in its path at a faster rate than the ants following a longer path [5], [6].
Pheromone is chemicals Article of acting exterior the body of ants of the secreting individual to manipulate the manners of ants [9].

\section{GENERAL CHARACTERISTICS OF ACO FOR ROUTING}

The following set of core properties characterizes ACO instances for routing problems [1], [5], [7], [9]:

- $\quad$ Provide traffic-adaptive and multipath routing.

- Rely on both passive and active information monitoring and gathering.

- Make use of stochastic components.

- Do not allow local estimates to have global impact.

- Set up paths in a less selfish way than impure shortest path schemes favoring load balancing.

- Show limited sensitivity to parameter settings.

\section{OBJECTIVE OF RESEARCH}

This research aims at: using ACO algorithm to find the optimal path from source node to destination node in networks.

\section{TOOLS AND SCOPE OF RESEARCH}

- Algorithm: Ant Colony Optimization

- Software: Microsoft Visual C\#.net 2010

- Case study: 9 states of different size networks $(10,15,20,25,30,40,50,60,75)$.

\section{ACO ALGORITHM FOR SOLVING NETWORKS ROUTING PROBLEM}

The proposed ACO technique for shortest path routing is illustrated in the block diagram shown in Figure (1), which describes the main procedures of the system. Microsoft Visual C\#.net 2010 was used for implementing the proposed system model. 


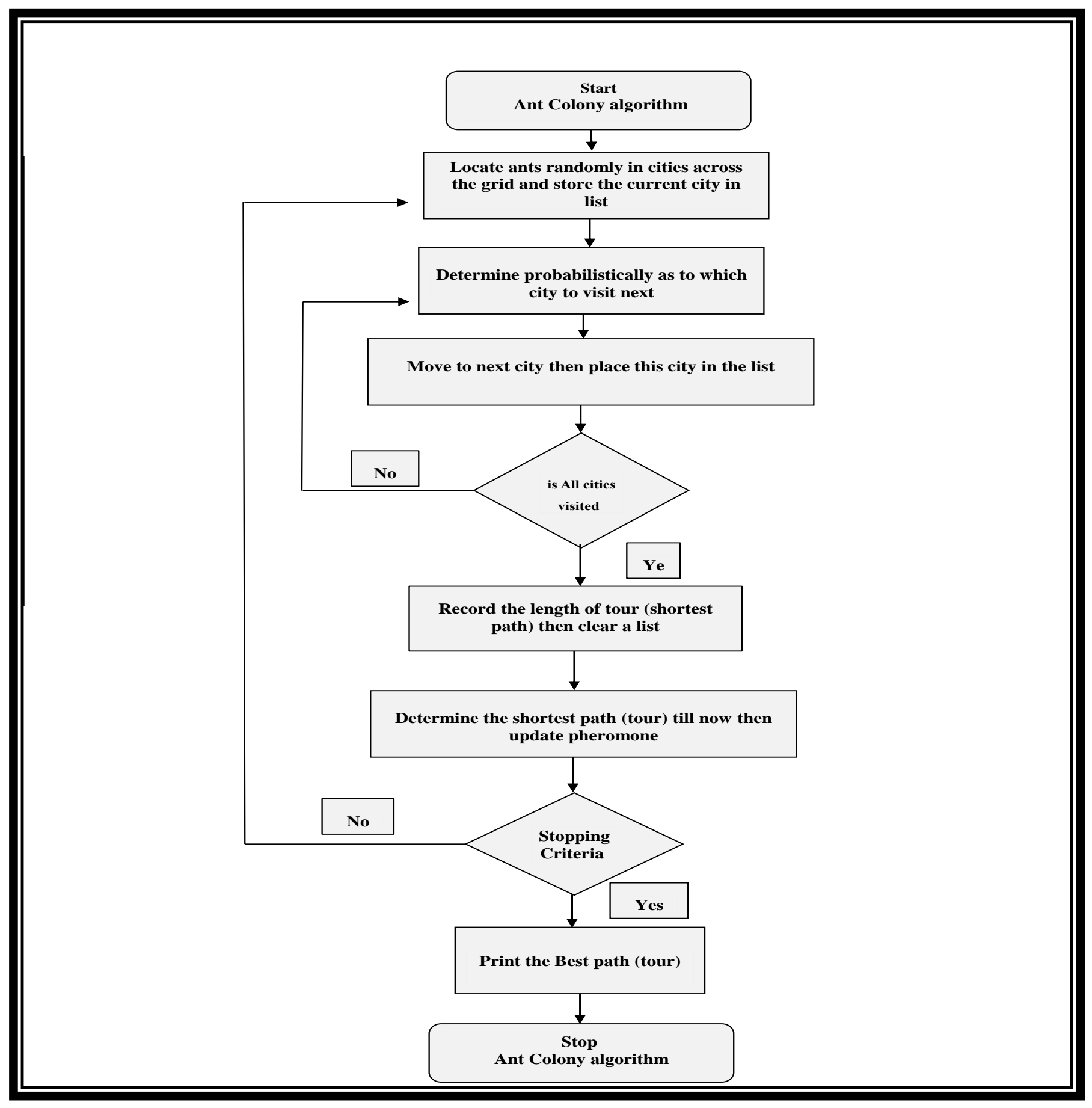

Figure (1): The Proposed Ant Colony Technique

\subsection{The results based on computer programming}

Tests are clearly indicated in Table (1) below.

Table (1): Testing results of the proposed system

\begin{tabular}{|c|c|c|c|l|c|}
\hline $\begin{array}{c}\text { No. } \\
\text { of } \\
\text { nodes }\end{array}$ & $\begin{array}{c}\text { Source } \\
\text { node }\end{array}$ & $\begin{array}{c}\text { destination } \\
\text { node }\end{array}$ & $\begin{array}{c}\text { Length of } \\
\text { optimal } \\
\text { path }\end{array}$ & $\begin{array}{c}\text { Optimal path } \\
\text { (trail) }\end{array}$ & Time/sec. \\
\hline 10 & 1 & 10 & 19 & $1,0,5,4,7,8,1,2,9,10$ & 2 \\
\hline 15 & 1 & 15 & 24 & $\begin{array}{l}1,9,14,13,6,7,3,1,11,12, \\
2,5,10,0,15\end{array}$ & 10 \\
\hline
\end{tabular}




\begin{tabular}{|c|c|c|c|c|c|}
\hline 20 & 1 & 20 & 24 & $\begin{array}{l}1,8,18,5,0,16,7,19,11,12 \\
, 1,6,17,9,13,4,10,15,14, \\
20\end{array}$ & 8 \\
\hline 25 & 1 & 25 & 32 & $\begin{array}{l}1,20,1,14,18,15,9,7,22,2 \\
, 17,12,16,23,13,11,6,5 \\
19,10,3,4,21,24,25\end{array}$ & 5 \\
\hline 30 & 1 & 30 & 34 & $\begin{array}{l}1,23,20,22,12,27,17,8 \\
15,14,16,0,24,26,13,21 \\
29,3,1,9,5,25,19,10,2,7 \\
11,18,4,30\end{array}$ & 8 \\
\hline 40 & 1 & 40 & 40 & $\begin{array}{l}1,11,25,12,8,29,37,15, \\
14,38,6,39,21,27,1,5,31, \\
23,3,13,26,7,9,17,28,4, \\
35,2,32,10,33,24,0,16, \\
18,34,19,36,40\end{array}$ & 16 \\
\hline 50 & 1 & 50 & 58 & $\begin{array}{l}1,28,1,17,12,39,13,24,0, \\
37,8,30,16,41,5,2,15,26, \\
45,36,43,44,10,21,11,19 \\
, 9,46,18,31,20,32,6,34, \\
48,27,, 25,29,14,42,7,47 \\
, 23,22,38,49,3,40,50\end{array}$ & 32 \\
\hline 60 & 1 & 60 & 62 & $\begin{array}{l}1,54,32,5,36,14,48,17, \\
15,11,19,27,45,39,31,50 \\
, 52,10,3,56,8,7,37,47,12 \\
, 22,9,41,29,44,40,16,55, \\
49,21,59,28,51,4,26,33 \\
30,58,57,18,46,35,43,0 \\
24,38,23,20,13,20,13,42 \\
, 34,53,6,60\end{array}$ & 91 \\
\hline 75 & 1 & 75 & 261 & $\begin{array}{l}1,14,17,11,21,36,5,73, \\
66,64,39,57,10,52,19,65 \\
, 33,54,72,47,62,51,24, \\
71,4,25,15,67,13,69,37, \\
60,1,23,42,20,34,48,22, \\
2,12,6,46,41,26,8,56,29, \\
74,18,61,44,53,49,3,7, \\
59,28,9,68,30,27,55,70, \\
32,43,45,50,2,58,35,40, \\
31,38,75 .\end{array}$ & 39 \\
\hline
\end{tabular}

\subsection{The steps for solving a problem by ACO are shown as follows}

1) Represent the problem in the form of sets of components and transitions, or by a set of weighted graphs, on which ants can build solutions.

2) Define the meaning of the pheromone trails

3) Define the heuristic preference for the ant while constructing a solution.

4) If possible implement an efficient local search algorithm for the problem to be solved.

5) Choose a specific ACO algorithm and apply to problem being solved.

6) Tune the parameter of the ACO algorithm.
Figure (2) and (3) demonstrates the visual interfaces of input ACO parameters and the obtained results respectively.

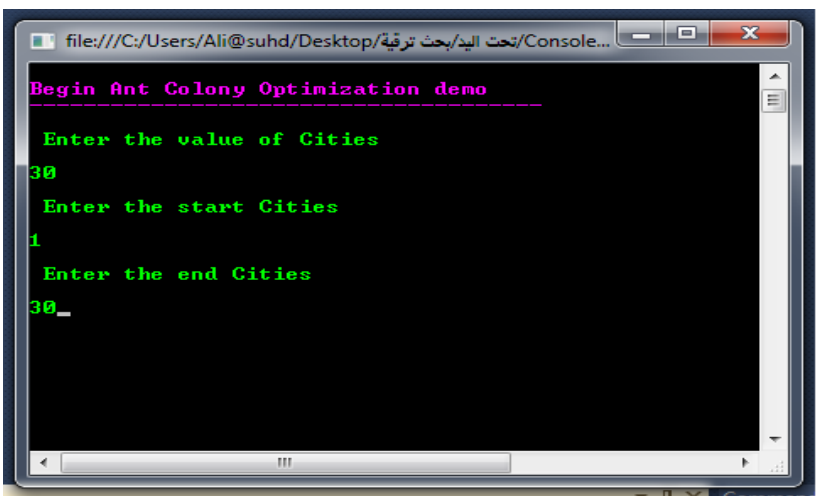

Figure (2): The implemetation of proposed algorithm 


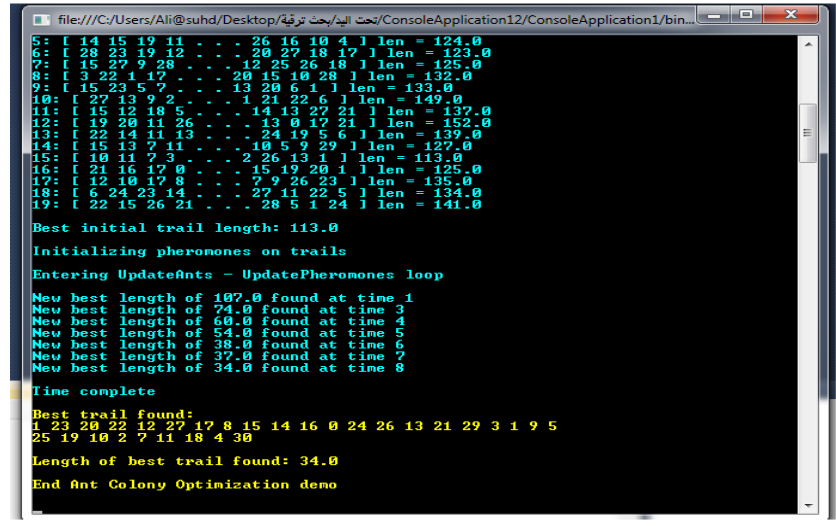

Figure (3): The implemetation of proposed algorithm

\section{CONCLUSIONS}

The proposed ACO algorithm is presented in this work to solve the routing problem. When the size of information transmitted over the network is increased there is a need to send it via shortest path in higher speed. Therefore, ACO algorithm is utilized to find the optimal solution (i.e., shortest path) to send information from source to destination passing through all nodes .According to the obtained results from the case studies, the proposed algorithm prove its success fullness for solving the routing problem with least computational time.

\section{REFERENCES}

[1] R.Geetha, and G. Srikanth, "Ant Colony optimization based Routing in various Networking DomainsASurvey", International Research Journal of Mobile and Wireless Communications, ICICES-2012-SAEC, Chennai, Tamilnadu, Vol 3, Issue 1; January-April,2012.

[2] Dalia Sabri," Performance Analysis for Network Coding Using Ant Colony Routing", Master of Philosophy,
Electronic and Computer Engineering, School of Engineering and Design, Brunel University, December, 2011.

[3] Xiao-Min Hu and Jun Zhang,"Minimum Cost Multicast Routing Using Ant Colony Optimization Algorithm", Hindawi Publishing Corporation, Mathematical Problems in Engineering, Article ID 432686, 18April, 2013.

[4] Marco dorigo and Thomas stuzle Bradford company scituate,MA "Ant colony optimization ", USA 2004 ISBN: 0262042193.

[5] Helio,J.C.Barbosa,Janeza"Ant colonyoptimizationtechniques and applications" Trdine9, 51000 Rijeka, Croatia, 2013.

[6] "Ant colony optimization - methods and applications" edited by Aviostfeld ISBN 978-953-307-157-2, Puplushed: February4, 2011 Under CC by-NC-SA3.0 License.

[7] C.W.Ahn,R.S.Ramakrishna,C.G.Kang.AndI.C.Choi."Sho rtestpath Routing algorithm using Hopfield Neural Network". Electron. Lett. Vol. 37 No. 19 PP. 1176-1178. Sept, 2001.

[8] Aboul Ella Hassanien ,Eid Emary"Swarm intelligence: principles, advances , and application" by CRC Press referenc-210pages-25 B/M IIustration ISBN78148741064-cat\#k26721. November 24,2015

[9] Computational intelligence methods and technique leszk ruttkowski, 2008.

[10] "Ant colony optimization" Edwin Wong, Phillip Summers, Rosalyn Ku, and Patrick Xie, PIC 10C Spring 2011. 